\title{
Problems Encountered and Academic Performance in Mathematics Subject of the Grade VI Pupils of Mariveles Elementary School, Dauis, Bohol
}

\author{
CAROLINA O. BELARMINO \\ http://orcid.org/0000-0002-8386-1070 \\ cobelarmino@universityofbohol.edu.ph \\ ANALIE M. BALABA \\ http://orcid.org/0000-0003-1055-0383 \\ analiebalaba@gmail.com \\ MA. ALMIRA C. QUIJADA \\ http://orcid.org/0000-0002-8999-6275 \\ malmiraquijada@gmail.com \\ JOYMEE ANN N. APOSTOL \\ http://orcid.org/0000-0003-4544-3203 \\ joymeeannapostol@gmail.com
}

MAYFLOR B. MADULIN

http://orcid.org/0000-0002-9844-8051

mayflormadulin@gmail.com

GLENDA Q. BADIANG

http://orcid.org/0000-0002-8208-9015

glendabadiang4@gmail.com 


\author{
NANCY M. GALBIZO \\ http://orcid.org/0000-0002-1268-9082 \\ galbizon@gmail.com
}

\begin{abstract}
JAINA MARIE CHELSEA O. ALCANO
http://orcid.org/0000-0003-2096-7721

alcanojmc18@gmail.com
\end{abstract}

\begin{abstract}
Mathematics is an essential part of people's daily lives and that nobody can do away with it. This study sought to discover the problems encountered and the academic performance in Mathematics of the Grade VI pupils in Mariveles, Elementary School in Mariveles, Dauis, Bohol. The respondents of this study were the 80 Grade VI pupils in Mariveles Elementary School aged 10-13 years old which were chosen through complete enumeration, but only 71 of them were able to answer the questionnaire. The design employed in the study was a descriptive-survey self-constructed questionnaire in Likert scale form as the primary instrument in identifying the problems encountered by pupils towards Mathematics subject, and a documentary analysis was used to determine the respondents' academic performance. T-test for uncorrelated means was utilized to in comparing the male and female respondents in terms of their problems encountered in mathematics and Pearson product-moment of correlation as statistical treatments for testing possible correlation between the academic performance and the problems encountered among the respondents. The results showed that the academic performance of the respondents in Mathematics was Satisfactory, Pearson $r$ shows that the academic performance and problems encountered were correlated and that the male and female respondents had a significant difference.
\end{abstract}

Keywords: Mathematics, academic performance, T-test for uncorrelated means, Pearson Product Moment Correlation

\title{
INTRODUCTION
}

People need Mathematics in counting, computing sales, gains and measuring areas and volume, and many more. The need to enhance 
pupils' mathematical skills and at the same time develop in them a positive attitude toward the subject is a dire academic need. It cannot be denied that mathematics plays an important role in life, but the reality is the majority of students find it very difficult to acquire the different mathematical skills and processes that are useful in their everyday lives. Some students view Mathematics as their Waterloo. As a result, students perform poorly in Mathematics (Ganal and Guiab, 2014). The Philippines lags behind other countries in Asia in terms of the results in the different tests administered here and abroad. One reason given was the unfavorable attitude of Filipino students towards Mathematics. Another reason pointed out is the lack of competent teachers who are a primary source of elementary learning in place of books and other learning material (Subia, Salangsang, \& Medrano, 2018).

Experiential learning as advocated by David Kolb (2014) is a powerful and proven approach to teaching and learning that is based on unquestionable reality: through experience, people will likely learn best. It is learning in which the learner is directly in touch with the realities being studied. The primary source of learning is emphasis often on direct sense experience and in-context action.

This theory implies that active involvement enhances students' learning. When students are actively engaged, they progress towards meaningful learning and successful mastery of key concepts. Thus, learning experiences should take account of the learner's level of development.

Self-efficacy theory by Albert Bandura (1977), states that whatever their form, psychological procedures alter the level and strength of selfefficacy. It is hypothesized that expectations of personal efficacy whether coping behavior will be initiated, how much effort will be expended, and how long it will be sustained is determined in the face of obstacles and aversive experiences.

This theory implies that for people to learn, they need the chance to learn about by trying new situations and ideas without being penalized or punished for mistakes which are very important to the activity of learning. The learning process needs the challenge of trying of the unknown, new and different experiences, and therefore, necessarily must involve the making of mistakes.

The Choice theory by William Glasser (1996), holds that all people need a sense of belongingness, freedom, fun, and power and that people can control their own behavior only. 
This explains that to motivate our students for learning, they should be given ample freedom to choose within parameters that are safe and responsible, developmentally appropriate, and supportive of learning for that is the ultimate purpose of freedom: to help our students learn and grow into the responsible persons they are called to be.

The Motivation theory by Abraham Maslow (1943) posits a series of viewpoints which should be incorporated in any sound theory of motivation is presented. The writer's theory, which is consonant with organismic theory, Gestalt psychology, and the beliefs of certain psychoanalytic schools, allows for a hierarchy of goals, purposes, or needs to be arranged in the following descending order of pre-potency: (1) basic bodily gratifications, (2) safety needs, (3) affection and acceptance, (4) feelings of adequacy and self-esteem, (5) self-actualization. When all wants are unsatisfied, the primary search for gratification will dominate all others in consciousness. When one want is satisfied, a new one, usually the next in the hierarchy, will emerge, although the satisfaction of any of these wants does not exclude the existence of any other.

This implies that highly motivated students enjoy learning and learn much more than one who is not motivated. Even when things turn out to be difficult, they persist and persevere in their studies. As a result, their performances are satisfactory.

A study by Acharya (2017) examined the tragedy faced by public school students in learning mathematics in their learning context. It stated that students, teachers, and parents had played the vital role as key provider of a sound environment for improvement of past rates. The leading causes of difficulties in learning Mathematics of teachers were: lack of linkage between new mathematical concepts and previously learned mathematics structure, mathematics anxiety, negative feeling of mathematics, economic condition and their educational backgrounds, school management system, lack of infrastructure and lack of regular assessment system of schools. (Acharya, 2017).

The achievement and interest in mathematics especially in higher mathematics, self - concept, the school and classroom atmosphere were ranked with a lower level of math anxiety. The index of economic, social, and cultural status was the only school factor that had minor but significant effects. The students' attitudes towards Mathematics can be divided into three clusters. The dimensions distinguishing the clusters are an interest in mathematics and math anxiety. The group that showed anxiety had the lowest 
the lowest score among the three clusters in math achievement (Radisic, Videnovic, \& Baucal, 2015).

Problems and difficulties that include personal issues (students' abilities and attitudes), instructional problems (teachers' strategies in teaching and attitude), family problems (finances and relationship), adjustment to college life, peer problems (adjustment to classmates and board mates), and cocurricular activities were reasons why learners had poor achievement in Mathematics. Mathematics forms a crucial discipline of teaching-learning programs because it is a way of thinking, a way of organizing a logical proof, and a powerful way of communicating. Thus, in a way that it fosters and nurtures the unique capabilities of students; the learning environment should be structured (Ganal and Guiab, 2014).

It is essential that critical thinking should be embodied and highlight in the curriculum when teaching Mathematics in school so that students could learn more skills and will apply it too. It could also improve students' performance and ability to reason out. If teachers firmly believe in introducing critical thinking skills in teaching Mathematics in the classrooms, then education program for teachers should also be distributed more courses for critical thinking so that expected teachers would become models of thinking strategies who in turn will make the subject easier for the students (Chukwuyenum, 2013).

According to Mata and Peixoto (2012), the study employs an adaption of the "Intrinsic Motivation Inventory" impose determinants of intrinsic motivation. "In my Math Class" one section of the questionnaire assesses student perceptions of teacher and peer support as well as student attitudes. In general, students held positive attitudes towards mathematics and highlighted the main effects of grade and math achievement on this attitude as a result revealed.

A state of discomfort associated with performing mathematical tasks is mathematics anxiety (MA). It is thought to affect a notable proportion of the school-age population. MA negatively affects mathematics performance according to some research. It has indicated that girls may report higher levels of MA than boys. On the other hand, boy's mathematics performance is more negatively affected by MA than girl's performance according to some research (Devine, Fawcett, Szücs, \& Dowker 2012).

According to Mbugua, Kibet, Muthaa, \& Nkonke (2012), students' performance in Mathematics has continuously been poor. Understaffing, insufficient teaching and learning materials, lack of motivation, retrogressive 
practices and poor attitudes by both teachers and students are one of the factors contributing to poor performance in Mathematics. If these said factors will have an improvement and the local community will be aware of these, it will help the students to have active participation in learning Mathematics.

The more motivated children were to do well in school for parentoriented reasons, the more involved parents were in children's learning contributed to children's enhanced self-regulated learning and thereby grades. It uniquely explained the positive effect of parents' involvement in children's grades, although children's parent-oriented motivation was associated with their controlled and autonomous motivation in school (Pomerantz and Cheung, 2012).

The administrators of the University of Bohol believe that people can always change. If there are problems encountered by the respondents in their Mathematics subject, as an educational institution, it assumes its responsibility to recommend and act upon those measures to address the gap and help improve the academic performance of Mathematics students. Hence, this study.

The study specifically sought to answer the following questions:

1. What is the profile of the respondents in terms of:

\subsection{Age;}

1.2 Sex?

2. What is the academic performance of the learners in Math subject?

3. What are the problems encountered by the respondents in Mathematics in the following areas:

3.1 Personal problems;

3.4 School factors;

3.2 Family factors; 3.5 Peer factors?

3.3 Teacher's instruction factors;

4. What are the common problems encountered of the respondents against different categories of ratings as to:

4.1 Academic Performance

4.1.1 Outstanding (90-100)

4.1.2 Very Satisfactory (85-89)

4.1.3 Satisfactory $(80-84)$

4.1.4 Fairly Satisfactory (75-79)

4.1.5 Did not meet expectations (Below 75)

4.2 Sex

4.2.1 Male 

4.2.2 Female
4.3 Age Range
4.3 .1 (10-12 yrs. old)
4.3.2 (13-15 yrs. old)

5 . Is there a significant degree of relationship between the problems encountered and academic performance among the respondents?

6 . Is there a significant degree of difference in the problems encountered between the male and female respondents?

7. What recommendations could be proposed based on the findings of the study?

\section{METHODOLOGY}

The descriptive-survey design employed in the study was a self-made questionnaire and some of its items were adapted and modified from (Ganal and Guiab, 2014), as the main instrument in identifying the problems encountered by pupils towards Mathematics subject and documentary analysis was used in determining the academic performance of pupils for the school year 2017-2018. Academic performance in Mathematics for the first and second grading period was obtained from the Grade VI Adviser. The study was conducted at Mariveles Elementary School, Mariveles, Dauis, Bohol which has a total population of 492 pupils. The respondents of the survey were the two sections of Grade VI which had a total population of 80 pupils. The researchers underwent ethics and plagiarism check at the research office, after which permission was secured from the University of Bohol - VP for Academics and the Dean of Teachers College, the DepEd Schools Division Superintendent, and lastly to the Principal of Mariveles Elementary School to conduct the study. Parents/ guardians were asked to sign a consent form, and the respondents themselves were also asked to sign an Assent Form that he/she agreed to his/her parents' consent. After the approval of the request, the researchers distributed the questionnaires to the respondents. The researchers assured that all data obtained would be held confidential and anonymous, and that the survey would not subject the pupils to any physical or emotional harm as a result. After all the questionnaires were retrieved, the data were tallied and tabulated, and further statistically treated using simple percentage, ranking, average weighted mean, Pearson-Product Moment Coefficient, t-test for uncorrelated mean to answer the specific problem. 
The level of academic performance was interpreted using the scale below:

\begin{tabular}{|c|c|}
\hline Academic performance range & Description \\
\hline $90-100$ & Outstanding \\
\hline $85-89$ & Very Satisfactory \\
\hline $80-84$ & Satisfactory \\
\hline $75-79$ & Fairly Satisfactory \\
\hline Below 75 & Did not meet expectations \\
\hline
\end{tabular}

The computed average weighted mean of the level of seriousness of the problem encountered was interpreted using the scale below:

\begin{tabular}{|c|c|}
\hline Range & Description \\
\hline $3.25-4.00$ & Very Serious \\
\hline $2.50-3.24$ & Moderately Serious \\
\hline $1.75-2.49$ & Slightly Serious \\
\hline $1.00-1.74$ & Not a Problem \\
\hline
\end{tabular}

\section{RESULTS AND DISCUSSION}

Table 1. Profile of the respondents

$(\mathrm{N}=71)$

\begin{tabular}{|c|c|l|c|c|c|c|c|}
\hline Items & F & Percentage & Rank & Items & F & Percentage & Rank \\
\hline \multicolumn{9}{|c|}{ Age } & \multicolumn{5}{c|}{ Sex } \\
\hline $10-12$ years old & 63 & $88.73 \%$ & 1 & Male & 54 & $76.06 \%$ & 1 \\
\hline $13-15$ years old & 8 & $11.27 \%$ & 2 & Female & 17 & $23.94 \%$ & 2 \\
\hline
\end{tabular}

As seen in table 1 , In terms of age, most of the respondents were 10 to 12 years old $(88.73 \%)$ while there were eight $(11.27 \%)$ who were between the ages 13 to 15 years old. In terms of sex, there were 54 (76.06\%) pupils who were males and 17 (23.94\%) who were females.

Table 2a. Summary of the academic performance of Grade VI pupils

$$
(\mathrm{N}=71)
$$

\begin{tabular}{|c|c|c|c|c|}
\hline & $\begin{array}{c}\text { First Grading } \\
\text { Period }\end{array}$ & $\begin{array}{c}\text { Second Grading } \\
\text { Period }\end{array}$ & $\begin{array}{c}\text { Mean Academic } \\
\text { Performance }\end{array}$ & $\begin{array}{c}\text { Qualitative } \\
\text { Description }\end{array}$ \\
\hline $\begin{array}{c}\text { Academic } \\
\text { Performance }\end{array}$ & 79.62 & 81.21 & 80.42 & Satisfactory \\
\hline
\end{tabular}


Table 2a indicates that the average academic performance during the first grading period was 79.62 which was lower than the performance during the second grading of 81.21 . The average was 80.42 indicating an over-all academic performance of Satisfactory.

Table $2 b$. Summary of the academic performance of Grade VI pupils according to the category on academic performance

\begin{tabular}{|l|l|l|l|l|l|}
\hline \multicolumn{9}{|c}{$(\mathrm{N}=71)$} \\
\hline $90-100$ & Outstanding & Value & F & Percentage & Rank \\
\hline $85-89$ & Very Satisfactory & VS & 10 & 14.08 & 3 \\
\hline $80-84$ & Satisfactory & S & 15 & 5.63 & 4 \\
\hline $75-79$ & Fairly Satisfactory & FS & 42 & 59.16 & 1 \\
\hline Below 75 & Did Not Meet Expectations & DNME & 0 & 0.00 & \\
\hline
\end{tabular}

Furthermore, Table 2b showed that 42 (59.16\%) had Fairly Satisfactory grade with the range $75-79,15$ (21.13\%) had Satisfactory grade with the range $80-84$, four $(5.63 \%)$ had Very Satisfactory grade with the range $85-89$. Moreover, ten students (14.08\%) had an Outstanding grade with the range 90-100. The students' average grade was described as Satisfactory with a general average of 80.42 .

Table 3. Summary of the problems encountered by the respondents $\mathrm{N}=71$

\begin{tabular}{|c|c|c|}
\hline Problems Encountered by the Respondents & Composite Mean & Rank \\
\hline Personal Factors & 2.42 & 1 \\
\hline Family Factors & 2.23 & 3 \\
\hline Teachers' Instruction Factors & 2.06 & 5 \\
\hline School Factors & 2.12 & 4 \\
\hline Peer Factors & 2.26 & 2 \\
\hline
\end{tabular}

Table 3 presents the summary of the problems encountered by the respondents. Personal factors ranked first with a composite mean of 2.42; followed by peer factors ranked second with a composite mean of 2.26; family factors was third with a composite mean of 2.23; school factors ranked fourth with a composite mean of 2.12; and teachers instruction factors ranked fifth with a composite mean of 2.06. 
Table 4. Summary of the common problems encountered by the pupils based on the categorization of academic performance

\begin{tabular}{|c|c|c|c|c|c|c|c|c|c|c|}
\hline \multirow[b]{2}{*}{$\begin{array}{c}\text { Problems } \\
\text { Encountered }\end{array}$} & \multicolumn{9}{|c|}{ Composite Mean } & \multirow[b]{2}{*}{ Rank } \\
\hline & $\begin{array}{c}0 \\
(10)\end{array}$ & Rank & $\begin{array}{l}\text { VS } \\
(4)\end{array}$ & Rank & $\begin{array}{c}S \\
(15)\end{array}$ & Rank & $\begin{array}{l}\text { FS } \\
(42)\end{array}$ & Rank & AVERAGE & \\
\hline Personal Factors & 1.88 & 1 & 2.13 & 1 & 2.51 & 1 & 2.51 & 1 & 2.26 & 1 \\
\hline Family Factors & 1.27 & 5 & 2 & 2.5 & 2.09 & 3 & 2.09 & 3 & 1.86 & 3 \\
\hline $\begin{array}{c}\text { Teachers' Instruction } \\
\text { Factors }\end{array}$ & 1.53 & 4 & 1.6 & 5 & 1.73 & 5 & 1.73 & 5 & 1.64 & 5 \\
\hline School Factors & 1.61 & 3 & 1.75 & 4 & 1.89 & 4 & 1.89 & 4 & 1.78 & 4 \\
\hline Peer Factors & 1.75 & 2 & 2 & 2.5 & 2.12 & 2 & 2.12 & 2 & 2 & 2 \\
\hline
\end{tabular}

Table 4 shows the common problems encountered by the pupils based on the categorization of academic performance in all factors. As reflected, personal factors ranked first with the composite mean of 2.26; followed by peer factors with the composite mean of 2; family factors ranked third with the composite mean of 1.86; school factors ranked fourth with the composite mean of 1.78; and teachers' instruction factors with the composite mean of 1.64 was last.

Table 5. Problems encountered by the pupils based on their age range

\begin{tabular}{|l|c|c|c|c|c|c|}
\hline \multirow{2}{*}{ Problems Encountered } & \multicolumn{5}{|c|}{ Composite Mean } & \multirow{2}{*}{ Rank } \\
\cline { 2 - 7 } & $\begin{array}{c}\mathbf{1 0 - 1 2} \\
\mathbf{( 6 3 )}\end{array}$ & Rank & $\begin{array}{c}\mathbf{1 3 - 1 5} \\
\mathbf{( 8 )}\end{array}$ & Rank & Average & \\
\hline Personal Factors & 2.40 & 1 & 2.61 & 1 & 2.51 & 1 \\
\hline Family Factors & 2.21 & 3 & 2.36 & 4 & 2.29 & 3.5 \\
\hline Teachers' Instruction Factors & 2.08 & 4 & 1.90 & 5 & 1.99 & 5 \\
\hline School Factors & 2.07 & 5 & 2.50 & 3 & 2.29 & 3.5 \\
\hline Peer Factors & 2.22 & 2 & 2.53 & 2 & 2.38 & 2 \\
\hline
\end{tabular}

Table 5 shows the common problems encountered by the pupils based on the categorization of their age range in all factors. As reflected, personal factors ranked first with the composite mean of 2.51; followed by peer factors with the composite mean of 2.38 ; family factors and school factors with a composite mean of 2.29 both ranked third; and teachers' instruction factors with the composite mean of 1.99 ranked last. 
Table 6. Problems encountered by the pupils based on their sex

\begin{tabular}{|l|c|c|c|c|c|c|}
\hline \multirow{2}{*}{$\begin{array}{c}\text { PROBLEMS } \\
\text { ENCOUNTERED }\end{array}$} & \multicolumn{5}{c|}{ COMPOSITE MEAN } & \multirow{2}{*}{ RANK } \\
\cline { 2 - 6 } & $\begin{array}{c}\text { MALE } \\
\mathbf{( 5 4 )}\end{array}$ & Rank & $\begin{array}{c}\text { FEMALE } \\
\mathbf{( 1 7 )}\end{array}$ & Rank & AVERAGE & \\
\hline Personal Factors & 2.48 & $\mathbf{1}$ & 2.22 & 1 & 2.35 & 1 \\
\hline Family Factors & 2.31 & 2 & 1.96 & 3 & 2.14 & 3 \\
\hline $\begin{array}{l}\text { Teachers' Instruction } \\
\text { Factors }\end{array}$ & 2.15 & 5 & 1.79 & 5 & 1.97 & 5 \\
\hline School Factors & 2.18 & 4 & 1.92 & 4 & 2.05 & 4 \\
\hline Peer Factors & 2.29 & 3 & 2.14 & 2 & 2.23 & 2 \\
\hline
\end{tabular}

Table 6 shows the common problems encountered by the pupils based on the categorization of their sex in all factors. As reflected, personal factors ranked first with the composite mean of 2.35; followed by peer factors with the composite mean of 2.23; family factors and school factors with a composite mean of 2.14, both ranked third; school factors with the composite mean of 2.05 ranked fourth; and teachers' instruction factors with the composite mean of 1.97 ranked fifth.

Table 7. Correlation between the problems encountered and academic performance among the Grade 6 pupils

\begin{tabular}{|c|c|c|c|c|c|}
\hline Respondents & $\begin{array}{c}\text { Problems } \\
\text { Encountered in } \\
\text { Mathematics }(X)\end{array}$ & $\begin{array}{l}\text { Academic Performance } \\
\text { (Y) }\end{array}$ & $\mathbf{X Y}$ & $\mathbf{X}^{2}$ & $\mathbf{Y}^{2}$ \\
\hline $\mathrm{N}=71$ & $\Sigma x=157.46$ & $\begin{array}{c}\Sigma y= \\
5709.5\end{array}$ & $\begin{array}{c}\sum x y= \\
12525.94\end{array}$ & $\begin{array}{c}\Sigma x^{2}= \\
364.226\end{array}$ & $\begin{array}{c}\sum y^{2}= \\
461470.3\end{array}$ \\
\hline \multicolumn{6}{|c|}{$r=(-) 0.72726$} \\
\hline \multicolumn{6}{|c|}{ Critical value of $r$ at $69 \mathrm{df}$ at alpha level $(0.05)$ is \pm 0.24819} \\
\hline \multicolumn{6}{|c|}{ Result=Significant } \\
\hline \multicolumn{6}{|c|}{ Null Hypothesis= Rejected } \\
\hline
\end{tabular}

The result of the computation in Table 7 showed that there was a significant relationship between problems encountered in Mathematics and academic performance. The computed Pearson $r$ was $(-) 0.72726$ beyond the critical value of \pm 0.24819 to be significant at 69 df at alpha level 0.05 level of significance hence, significant. The result did not coincide with the hypothesis. This result means that the more serious the problems encountered in Mathematics, the lower was the academic performance. 
Table 8. Significant difference between the responses of male and female respondents

\begin{tabular}{|c|c|}
\hline Male Responses & Female Responses \\
\hline AVERAGE $=2.28$ & AVERAGE $=2.01$ \\
\hline \multicolumn{2}{|c|}{$t=2.1946$} \\
\hline \multicolumn{2}{|c|}{ Critical value of $t$ at $69 \mathrm{df}$ at alpha level $(0.05)$ is 1.960} \\
\hline \multicolumn{2}{|c|}{ Result= Significant } \\
\hline \multicolumn{2}{|c|}{ Null Hypothesis= Rejected } \\
\hline
\end{tabular}

The results of the computation in Table 8 showHGla significant difference between the responses of male and female as to problems encountered in Mathematics. The computed $t$ of Sroblems Hcountered in Mathematics was 2.1946 slightly higher than the required table of 1.960 to be significant at $69 \mathrm{df}$ at alpha level .05 level of significance hence, VJQLIFDQWThus, the null hypothesis is rejected. It ZDV observed that maleVl encountered serious problems in Mathematics more Z $\mathrm{L} W D Q$ average of 2.28 as a group FRP SDHGM femaleV which haGDQ average of 2.08.

In terms of age, the majority of the pupils are within the age range of 10-12 years old. As to sex, it showed that the number of male pupils is greater than female. The pupils' mean academic performance was $80.42 \square$ RUdescribed as Satisfactory. GradeV with the range of 75-79 described as Fairly Satisfactory ranked[ILWhollowed by Satisfactory Z LKOJUDGHWwithin the range of 80-84; Outstanding $\mathrm{RU}$ gradeV within the range of 90-100

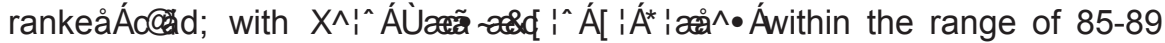
rankHG DWN This finding revealed that pupils performed poorly in Mathematics subject. This finding runs parallel to the findings of Subia et al., (2018, that the performance of the respondents in Mathematics 1 was below average (82.10). This finding conveys that the respondents were weak in Mathematics. In line with the Motivation theory by Maslow (1943), a highly motivated student learns much more and enjoys learning than the student who is not as motivated.

Pertaining to the problems encountered by the pupils in Mathematics, personal factors ranked first with a composite mean of 2.42 ; followed by family factors ranked second with a composite mean of 2.23; teachers' instruction factors was third with a composite mean of 2.06; school factors ranked fourth with a composite mean of 2.12; peer factors ranked fifth with a composite mean of 2.26 . This result means that the pupils encountered 
problems mostly on personal factors. It is similar to the findings of Ganal and Guiab (2014) which stated that poor achievement in Mathematics is caused by problems and difficulties that include personal problems, psychological problems, instructional problems, family problems and peer problems. In line with Choice theory by Glasser (1996), every student will more likely love to go to school if we make them feel that they belong to that classroom community and if we create a sense of community in a classroom.

\section{Common Problems Encountered by the Pupils Based on the Categorization of Academic Performance}

The common problems encountered by the pupils against different categories of ratings as to academic performance was personal factors. Most of the respondents whose academic performance were described as Outstanding encountered problems relating to poor study habits, feeling of hesitation to answer Mathematics activities due to fear and anxiety, and found Mathematics test questions more difficult compared to other subject questions. On the other hand, pupils encountered less difficulty in lack of appropriate learning materials, afraid of not gaining good impression from the teacher and less focus in studying Math due to a feeling of hunger. While the pupils who had an average grade of Fairly Satisfactory encountered difficulties relating to lack of appropriate learning materials, feeling of hesitation to answer Math activities due to fear and anxiety, and easily discouraged when he/she got a low score. On the other hand, pupils encountered less difficulty relating to lack of interest toward the subject, found math test questions more difficult compared to other subject questions, and had a feeling of unease and restlessness towards Mathematics subject. The findings of this study are in contrast with the findings of Ganal and Guiab (2014), because as reflected, school expenses ranked first or was the most common problem of 46 respondents (19.17\%); followed by lack of interest and negative attitude in the subject with 43 respondents (17.92\%); poor study habits ranked fourth with 42 respondents $(17.50 \%)$; being away from parents, siblings and relatives was fifth with 20 respondents $(8.33 \%)$. In line with the Experiential learning theory by Kolb (2014), "people learn best through experience," is an incontrovertible reality that served as the basis of experiential learning that is a powerful and proven approach to teaching and learning. 


\section{Common Problems Encountered by the Pupils Based on their Age Range}

The common problems encountered by the pupils against different categories of ratings as to their age range was personal factors. The pupils who were at the age range 10-12 years old encountered problems relating to poor study habits, feeling of hesitation to answer Mathematics activities due to fear and anxiety, and found math test questions more difficult compared to other subject questions. On the other hand, pupils encountered less difficulty relating to afraid of not gaining good impression from the teacher, less focus in studying Math due to a feeling of hunger and feeling of unease and restlessness towards Mathematics subject. While the pupils who were at the age range of 13-15 years old encountered difficulty such as poor study habits, find Mathematics test questions more difficult compared to other subject questions and easily discouraged when they got a low score. On the other hand, pupils encountered less difficulty such as not believing in one's capabilities, feeling of unease and restlessness towards Mathematics subject and less focus in studying Math due to a feeling of hunger. It is somewhat similar to the findings of Nicolaidou and Philippou (2003) that due to frequent and repeated failure or problems, the results are negative attitudes when dealing with mathematical tasks and these negative attitudes may become relatively permanent. In line with Selfefficacy theory by Albert Bandura, students are more likely to be intrinsically motivated to do learning activities if they believe that they can perform such learning activities successfully.

\section{Common Problems Encountered by The Pupils Based on Their Sex}

The common problems encountered by the pupils against different categories of ratings as to their sex was personal factors. The male pupils who numbered more encountered problems relating to poor study habits, feeling of hesitation to answer Math activities due to fear and anxiety, found Mathematics test questions more difficult compared to other subject questions, and lack of interest towards the subject. On the other hand, male pupils encountered less difficulty relating to being afraid of not gaining good impression from the teacher, less focus in studying Math due to a feeling of hunger and feeling of unease and restlessness towards Mathematics subject. While the female pupils encountered difficulty such as lack of appropriate learning materials, poor study habits, and less focus in studying Math due to a feeling of hunger. On the other hand, female 
pupils encountered less difficulty such as not believing in their capabilities, found Mathematics test questions more difficult compared to other subject questions and feeling of unease and restlessness towards Mathematics subject. It is in contrast to the study of Adimora, Nwokenna, Omeje \& Eze (2015) that women experience more anxiety in mathematics as a group than men. In line with Motivation theory by Maslow, without being pushed by his/ her teachers and parents, a highly motivated student takes the initiative to undertake assignments, learning task and projects.

\section{Relationship between the Problems Encountered and Academic Performance in Mathematics}

There was a significant relationship between problems encountered and academic performance in Mathematics. This result was attested by the computed Pearson $r$ value of $(-) 0.72726$ higher than the required critical value of \pm 0.24819 to be significant at $69 \mathrm{df}(0.05)$. The result did not coincide with the null hypothesis. This finding means that the higher the problems encountered in Mathematics, the lesser the academic performance in Mathematics. It is similar to the study of Ganal and Guiab (2014). Further, such result reaffirms that poor achievement in Mathematics is caused by problems and difficulties that included personal problems, psychological problems, instructional problems, family problems and peer problems. In line with Motivation theory by Maslow, a highly motivated student learns much more and enjoys learning than the student who is not as motivated.

\section{Difference between Male and Female Pupils in terms of Problems Encountered in Mathematics}

There was a significant difference between male and female as to problems encountered in Mathematics. This result was attested by the computed t-value of 2.1946 which was slightly higher than the tcritical value of 1.960 at $69 \mathrm{df}(.05)$. Thus, the null hypothesis was rejected. It has been observed that male pupils encountered problems in Mathematics more which has the average of 2.28 as a group than female which has the average of 2.01. It is in contrast to the study of Adimora et al., (2015), where women experienced more anxiety in Mathematics as a group than men. In line with Experiential learning theory by David Kolb, "people learn best through experience," is an incontrovertible reality that served as the basis of experiential learning that is a powerful and proven approach to teaching and learning. 


\section{CONCLUSION}

The research findings provided sufficient evidence that personal factors were the main causes of poor achievement of the pupils in Mathematics subject. Male pupils encountered difficulty in Mathematics more than females. Academic performance is correlated with problems encountered by the learners. Pupils with different academic categories encountered common problems relating to poor study habits, hesitation in answering Math activities due to fear and anxiety, lack of appropriate learning materials and found Math test questions more difficult compared to test questions of other subjects. Also, the pupils encountered less difficulties relating to not believing in one's capabilities, feeling of unease and restlessness towards Math and lack of focus on studying Math due to hunger.

\section{RECOMMENDATIONS}

Based on the above conclusions, the researchers recommend that:

1. Students must be taught to learn the value of serious study, how to work independently and to manage their time wisely. They must realize their responsibility in the learning process.

2. Parents should assist their children in establishing proper time management, skills for completing homework assignments and projects, reading, and preparing for exams. They are encouraged to collect all cellphones, laptops, and tablets (unless of course, they are used for learning) during study time to remove the educational roadblock. Furthermore, parents should provide a quiet place for study in their homes to create an environment conducive to learning.

3. Teachers should assign only meaningful and achievable worked geared to the interests, talents, and abilities of students. They should guide the students to come up with purposeful ideas instead of rejecting the wrong answers of the students. Throwing thoughtprovoking questions and giving clues will help the students to attain success in Mathematics.

4. Teachers are encouraged to participate in Continuing Professional Development programs to update themselves with the latest pedagogical strategies and relate Mathematics to real-life situations. 
5. Diagnostic examinations must be conducted at the beginning of the school year to identify the learners' difficulties in Mathematics. Remedial classes and collaborative activities are suggested to target motivating and boosting students' confidence in solving Mathematical problems and helping them to develop their Mathematical skills.

6. The Guidance Center should include in the curriculum the emphasis on Self-Concept and Esteem and Personality Development that would enhance the pupil's confidence. Integration of values in all subject areas must be stressed for the pupils to learn the importance of unity, sharing and compassion for their classmates who have difficulty in some subject areas.

\section{REFERENCES CITED}

Acharya, B. (2017). Factors Affecting Difficulties in Learning Mathematics by Mathematics Learners.6, 8-15. Retrieved from https://goo.gl/eK7QGL, (accessed last 10 February 2018).

Adimora, D. A., Nwokenna, E.N., Omeje, J.C., \& Eze, U. N. (2015). Influence of Socio-Economic Status and Classroom Climate on Mathematics Anxiety of Primary School Pupils. Elsevier Ltd, 693-701. Retrieved from https://goo.gl/rf53VE, (accessed last 15 February 2018).

Bandura, A. (1977). Self-efficacy: Toward a unifying theory of behavioral change. Psychological Review, 84(2), 191-215. Retrieved from https:// goo.gl/UFB71z, (accessed last 10 February 2018).

Chukwuyenum, A. (2013). Impact of Critical thinkin g on Performance in Mathematics among Senior Secondary School Students in Lagos State. IOSR Journal of Research \& Method in Education (IOSR - JRME), 3(5), 18-25. Retrieved from https://goo.gl/qvGviL, (accessed last 15 February 2018).

Devine, A., Fawcett, K., Szücs, D., \& Dowker, A. (2012). Gender differences differences in mathematics anxiety and the relation to mathematics performance while controlling for test anxiety. Behavioral and brain functions, 8(1), 33. Retrieved from https:// goo.gl/B2nHZi, (accessed last 15 Februrary 2018). 
Ganal, N. N., Guiab, M.R. (2014). PROBLEMS AND DIFFICULTIES ENCOUNTERED BY STUDENTS TOWARDS MASTERING LEARNING COMPETENCIES IN MATHEMATICS. Researchers World-Journal of Arts, Science \& Commerce, V(4), 25-37. Retrieved from https://goo.gl/ VhVUHd, (accessed last 15 February 2018).

Glasser, William. (1996). Then and Now. The theory of Choice. 25, 20-22. Retrieved from https://bit.ly/2J7y5dd, (accessed last 10 February 2018).

Kolb, D. (2014). Experential Learning: Experience as the source of learning and development, FT Press. Retrieved from https://bit.ly/2uwbVy5, (accessed last 15 February 2018).

Maslow, A. H. (1943). Preface to Motivation theory. APA PsycNet, 85-92. Retrieved from https://goo.gl/fswUuP, (accessed last 15 February 2018).

Mata, M., Monteiro, V., \& Peixoto, F. (2012). Attitudes towards Mathematics: Effects of Individual, Motivational, and Social Support Factors. Attitudes towards Mathematics: Effects of Individual, Motivational, and Social Support Factors,2012, 1-10. Retrieved from https://goo.gl/ptr6AM, (accessed last 15 February 2018).

Mbugua, Z., Kibet, K., Muthaa, G., \& Nkonke, G. (2012). Factors Contributing To Students' Poor Performance in Mathematics at Kenya Certificate of Secondary Education in Kenya: A Case of Baringo County, Kenya. American International Journal of Contemporary Research, 2, 6th ser., 87-91. Retrieved from http://bit.ly/2FJMLhr, (accessed last 2 February 2018).

Nicolaidou, M., \& Philippou, G. (2003). Attitudes towards Mathematics, selfefficacy and achievement in problem solving. European Research in Mathematics III, 1-11. Retrieved from https://bit.ly/2uCMgng, (accessed last 15 February 2018). 
Pomerantz, E. M., \& Cheung, C. S. (2012). Why does parents' involvement enhance children's achievement? The role of parent-oriented motivation. Journal of Educational Psychology, Journal of Educational Psychology, 820-832. Retrieved from http://bit.ly/2CRIAwY, (accessed last 15 February 2018).

Radisic, J., Videnovic, M., \& Baucal, A. (2015). Math anxiety- contributing school and individual level factors. Math anxiety- contributing school and individual level factors, 30(1), 1-20. Retrieved from http://bit. ly/2Gev0ac, (accessed last 10 February 2018).

Subia, G.S., Salangsang, L., \& Medrano, H.B. (2018). Attitude And Performance In Mathematics Of Bachelor Of Elementary Education Students: Acorrelational Analysis. American Scientific Research Journal for Engineering, Technology and Sciences, 39, $1^{\text {st }}$ ser., 206213. Retrieved from https://goo.gl/Jc57Zq, (accessed last 28 February 2018). 